\title{
Challenge-based gamification and its impact in teaching mathematical modeling
}

\author{
Elvira G. Rincón Flores \\ Escuela de Ingeniería y Tecnología de Escuela de Educación, Humanidades \\ la Información \\ Tecnológico de Monterrey \\ Avda. Garza Sada 2501 sur; col. \\ Tecnológico \\ Monterrey, N. L. México; CP64849 \\ elvira.rincon@itesm.mx
}

\author{
Juanjo Mena \\ Facultad de Educación \\ Universidad de Salamanca \\ $\mathrm{P}^{\circ}$ de Canalejas, 169, 37008, \\ Salamanca (España) \\ juanjo_mena@usal.es
}

\begin{abstract}
The research presented describes how the challenge-based gamification strategy contributes to meaningful learning of the calculation of solids of revolution spreads in a subject in engineering. The evaluation of students' performance during the gamification activities followed the mathematical modeling cycle. The research was carried out during the semester from January to May 2016 where 48 students from Engineering and Integral Calculus Courses in Tecnólogico de Monterrey (Mexico) participated. The students were divided into two groups, each consisting of 24 students and grouped in teams of four people. Three gamification activities were applied throughout the course. Mix Methods were chosen to analyze data. Main results indicate that challenge-based gamification help students were able to apply solids of revolution both in its application and the algorithmic part.
\end{abstract}

Keywords

Gamification, Challenge based learning, Problem Solution, Modeling.

\section{INTRODUCTION}

In the teaching of Mathematics teachers have made efforts to improve student learning and further improve attitudes towards this discipline. [9] argues that innovation is a teaching mechanism that proposes strategies that work and that are easily communicated to others. However, innovation not only involves improving teaching techniques or introducing new teaching technologies or strategies [31] but also developing real changes that stimulate learning $[14,15,16,29]$.

In recent years the teaching strategy of Gamification has been gaining more strength thanks to the ludic element that characterizes it. The game is a universal activity and has been present in various areas such as art, sport and science [10,25,32]. Throughout history, mathematics has had a recreational component. For example, Pascal, Fermat, and Gauss (among others) participated in mathematical challenges, which could be seen as incipient challenge-based gamification [17]. As Gamification uses the ludic elements of the teaching process (e.g., videogames), it has become a teaching strategy that can potentiate the commitment (engagement) of the learners.

In education it is used with the purpose to place the student in scenarios involving challenges and exciting missions to increase their level of commitment and competitiveness $[18,24]$ either as digital resource designed for a didactic purpose or to take its elements and integrate them into educational activities through simulations [2,22].

In this sense, the challenges based learning can be an element that complements the gamification and vice-versa. A challenge is a hard problem or situation in which a student finds his/herself into. The student must solve this challenge through the application of what they have learned $[2,24]$. Thus, both strategies can converge in what has been classified as challenge based gamification, as Gamification motivates a student's engagement [5]. Learning based on challenges encourages creativity in problem solving determining the level of learning achieved [23].

The purpose of this paper is to show the advantages of challenge based gamification in the learning of integral calculus for mathematics and engineering students in a higher education institution. We specifically focused on the subject content of solids of revolution calculus with the strategy of the differential take [1]. It also shows whether the short-term learning stayed valid long-term taking as reference the phases of the modeling routes from $[7,8]$. 


\section{THEORETICAL FRAMEWORK 2.1 From play to gamification}

The game is an activity performed by people of all ages and from all over the world. In a study by [33] on types of games and play areas, they found that it is an activity practiced from childhood to adulthood and that it has been adapted over time, mixing with different cultures and responding to the historical moment. In childhood, playing is a need. However in adulthood, playing is not just a matter of releasing energy, it develops a range of human skills $[4,32]$. Therefore, we can say that the game can be applied in any educational level as well as in any learning space.

In education, although playing was not considered ethic for learning in the past, it is becoming more relevant every time and we can even glimpse its evolution. Games help to experiment, explore options and consequences and test own limits. This allows to create situations of high educational value because it enhances students' motivation and interest [26]. [28] claim that educational games are a unique opportunity to merge into learning the cognitive, affective and social aspects. Thus playful learning has become a powerful tool to improve the classroom environment.

Currently, playing has become more sophisticated resulting in gamification and "serious games" (inspired on video games). Gamification takes elements and mechanics of playing, and it was born thanks to the digital age and the benefits of playing [21]. The term was coined by Nick Pelling in 2002 but did not become popular until 2010 due to the reward systems in digital environments offered by the business and commercial sectors [30]. Years later, gamification began to be included into the educational environment around the world which has generated interest and skepticism in academic communities, particularly in the teaching and learning of mathematics.

Many research works show the benefits of gamification in education. For example, [20] performed a meta-analysis about the use of gamification as mathematics learning strategy from 2003 to 2017. Out of the 16 performed investigations, 11 had positive results while five had positive as well as negative results. [10,26] found some advantages of using games in mathematics courses, which can be highlighted: arouse curiosity, promote social development, constitute a means to achieve an educational objective, stimulate the imagination and can be generators of lasting learning. For [18], gamification is an important ally because it can be applied in education to motivate and use new ways to enjoy activities that are often tedious, which is very convenient when addressing complex mathematical topics.

Gamification have valuable elements for the students' well-rounded education. [13],27] agree that playing is a unique opportunity to integrate cognitive, emotional and social aspects. These angles are to be considered when designing gamified activities.

\subsection{Mathematical Modeling.}

The basic antecedents behind the vision of Mathematical Modeling are supported on the work by [6,7,8,19] who initially present Mathematical Modeling as the relationship between Mathematics and "reality" (See Figure 1).

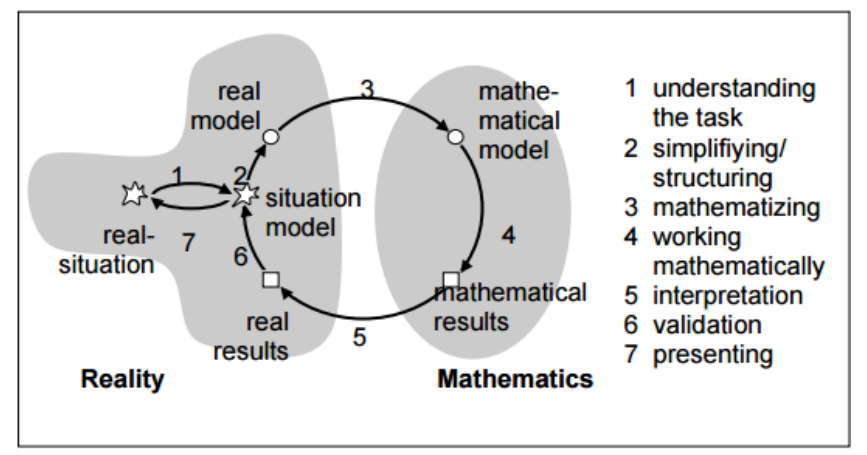

Figure 1. Phases of the modeling cycle. [7]

At first, the student must understand the situation or actual problem. It is when the model begins to be built through approaches or graphic sketches (phase 1). Next, the problem-situation becomes more accurate through a simplification process towards a real model (phase 2). Then, the mathematization process becomes the real model in a mathematical model which is generally one or a set of equations of different types, for example algebraic and differential (phase 3). The solution of this model is achieved through mathematical work (phase 4). The obtained solution allows to interpret the actual situation (phase 5). The results are verified against the actual problem situation (phase 6) and finally the student can present the problem and its solution (phase 7). 


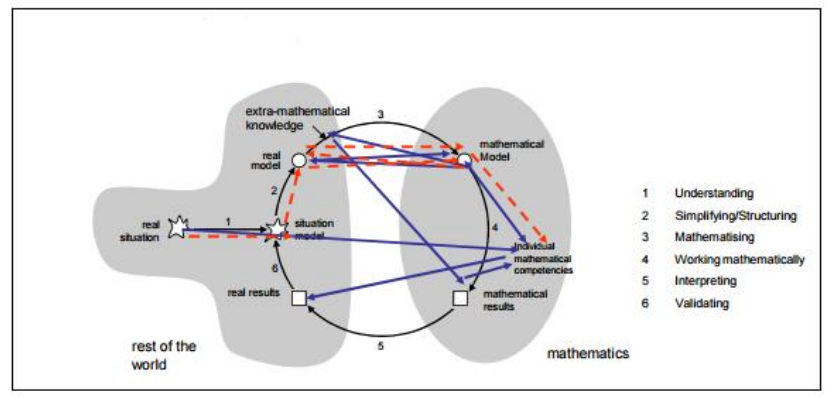

Figure 2. Routes examples as explained by $[7,8]$

Following a more detailed analysis of other authors that propose to visualize mathematical modeling from another point of view, this study intends to continue this, adopting the description of learning paths developed by [8] on the modeling cycle of [7] in terms of seven stages in which it is stated that they are nonlinear, see Figure 2. It is important to consider the latter since it is proved in practice.

\section{METHODOLOGY}

For the development of this research, we will use the mixed research method [11,12], because both, quantitative and qualitative methods complement themselves and offer a deeper study of the phenomenon of study. The research was carried out during the semester from January to May 2016 where 48 students from Engineering and Integral Calculus Courses in Tecnológico de Monterrey (Mexico) participated. The students were divided into two groups, each consisting of 24 students and grouped in teams of four people. The subject of Integral Calculus is based on the understanding of the integral through the strategy of the differential take [1], its application in the engineering context as well as the algorithmic development of integration techniques.

Task design. The study was divided into three phases: (1) gamified activity; (2) partial test and (3) final exam. In the first phase, a gamified activity was presented. This activity consisted of three activities with progressive difficulty level. When a team finished the first level activity with both process and result correct, that team gained one point and passed to the next level (this goes on and on as the team advances levels). The progress of each team was projected in a display board so that it was visible to all participants (Figure 3).

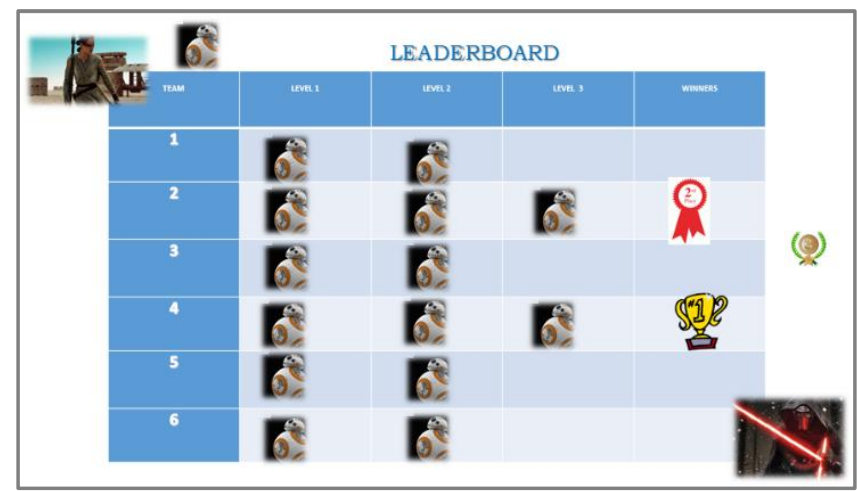

Figure 3: Leaderboard of the progress of one of the groups.

The winning team, which was the team that finished first and correctly completed the third level won the trophy shown on the board, won an additional prize (symbolic). The development of each challenge was guided according to the model of [7].

The challenge of the activity of the first level consisted of using clay to model the top of a cup and cutting a differential volume to relate the elements that are present in a cylinder (radius and height) with the mathematical function that describes the shape of a cup (construction stages and simplification). Then, they proceeded to propose the volume of the differential and the integral that gives the total volume (step of mathematization). After this, they solved the integral (step of mathematical work), interpreted their result (step of interpretation), proved the result using elementary geometry or employing some mathematical application (step of validation) and finally, they explained the process of how they reached their result (step of explanation) obtaining the general integral to get the volume of solid of revolution which rotates 
around $x$. The didactic purpose is that while using concrete material students succeed in understanding the role of differential and the symbolic importance of $d x$, see Figure 4.

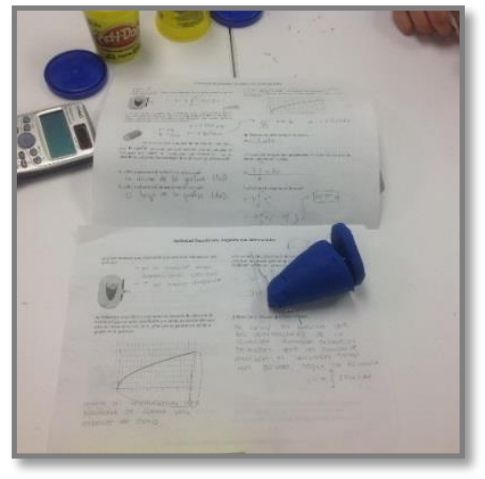

Figure 4. Activity performed by the students.

The challenge of the second activity consists of implementation of the integral built in level 1 to a particular context (calculation of the volume of a flask) and the activity of the third level was composed of another application in which the students should calculate the volume of a knob that was formed by three functions. This elevated the challenge level. Figure 5 shows a moment of the gamified activity.

The second and third phase consisted of an exercise included in one of the partial exams and the final exam, respectively. These exercises were evaluated following the same phases of the challenge based gamified activities.

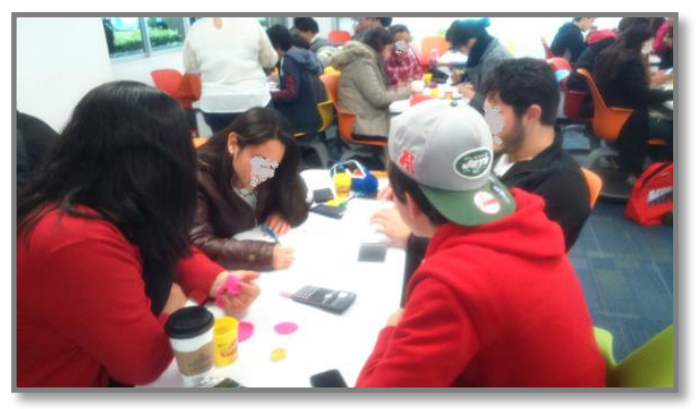

Figure 5. Students during a gamified activity.

Data gathering and analysis. The exercises included in the partial and final exams were analyzed in order to test if the learning was kept long-term. On the other hand, field notes were gathered in each one of the sessions through an observation procedure.

Quantitative and qualitative analysis was performed. First, we examine the mathematical procedures developed in each exercise on the partial and final exams. Then, the qualitative analysis was conducted. For this, the following hypotheses set is proposed:

$H_{0}: \mu_{1}=\mu_{2}$ Students' performance in the partial and the final exams is the same.

$H_{1}: \mu_{1} \neq \mu_{2}$ Students' performance in the partial exam is different from the performance in the final exam (being higher in the final)

This translates into testing if short term learning $\left(\bar{x}_{1}\right)$ and long-term learning $\left(\overline{x_{2}}\right)$ are consistent, in other words, if learning was kept longterm. The test Anderson Darling was used to validate if the data followed a normal distribution.

The field notes were analyzed considering several dimensions: cognitive, affective and social. According to [13] and [27] these dimensions must be present in every gamified activity.

\section{RESULTS}

Table 1 summarizes the descriptive statistics (mean and variance) obtained from the qualitative analysis of the evaluation of the exercise solved in the partial and final exams by the 48 participants of the study. The analysis includes each of the routes phases of mathematical modeling by [8]. 
Table 1. Descriptive statistics results (mean and variance) per each phase of the partial (1) and final exam (2).

\begin{tabular}{|l|l|l|l|l|}
\hline Phase & $\overline{x_{1}}$ & $s_{1}^{2}$ & $\overline{x_{2}}$ & $s_{2}^{2}$ \\
\hline Construction & 8.22 & 14.4 & 8.46 & 6.25 \\
\hline Simplification & 8.96 & 9.53 & 9.25 & 3 \\
\hline Mathematization & 9.21 & 8.14 & 9.06 & 3.02 \\
\hline $\begin{array}{l}\text { Mathematical } \\
\text { Work }\end{array}$ & 8.06 & 7.17 & 9.42 & 3.31 \\
\hline Interpretation & 8.02 & 7.17 & 9.8 & 1.02 \\
\hline Validation & 7.92 & 8.72 & 8.17 & 14.73 \\
\hline Presentation & 9.67 & 0.86 & 9.96 & 0.08 \\
\hline
\end{tabular}

As it can be seen in Table 1, mathematization phase has less mean and variance in the final exam. It is worth noting that the opposite happens with the validation phase for which mean and variance are higher in the final exam.

Table 2 summarizes the inferential statistics performed over the data. We applied normality tests to each data group, that is, to each phase as well as to the partial and final exams. Results showed that not a single data group follows a normal distribution (Figure 6 shows an example).

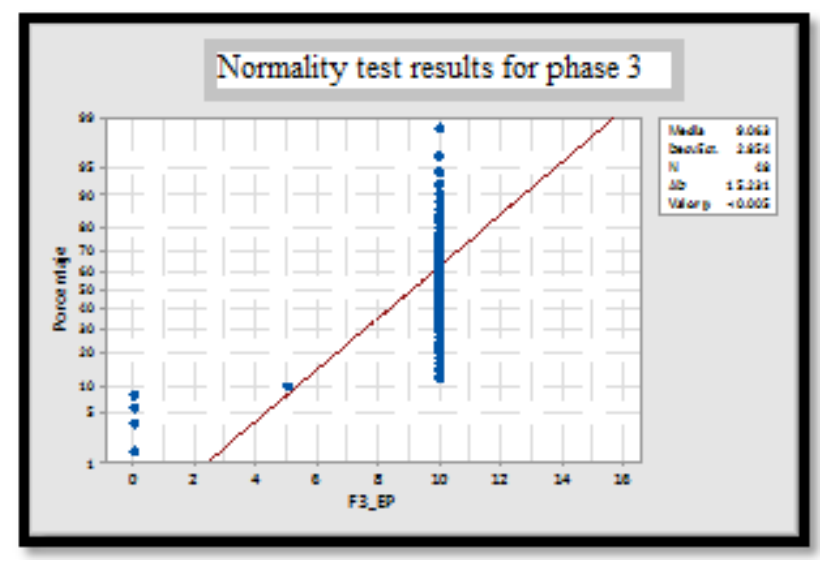

Figure 6. Normality test results for phase 3: Mathematization in the partial exam.

Therefore, a non-parametric Mann-Whitney U test was used. We set the significance level to 5\%. Results are shown in Table 2.

Table 2. Inferential Statistics using the non-parametric Mann-Whitney U test (figures below the 5\% significance level are in bolt font). ** Statistical significance at the 0.01 level

\begin{tabular}{ll} 
Phase & P value \\
\hline P1. Construction & 0.4005 \\
P2. Simplification & 0.5255 \\
P3. Mathematization & 0.5776 \\
P4. Mathematical Work & 0.1214 \\
P5. Interpretation & $0.0001 * *$ \\
P6. Validation & $0.0002 * *$ \\
P7. Presentation & 0.0510 \\
\hline
\end{tabular}

As shown in Table 2, significant values P5 and P6 invite us to reject the null hypothesis. However, most of the phases results are not statistically significant.

As for the observations made during the gamified session, you can highlight that the cognitive dimension played an important role. This is because each level represented a challenge that was increasing in difficulty as they advanced, favoring the student's commitment (engagement) with the activity [17]. In the dimension regarding affectivity it was observed that having an immediate evaluation in each activity or level, students are encouraged to continue in case of a favorable response. In other cases, they were observed entering a 
metacognitive process so that they questioned what they had to correct or improve [13]. In other teams, discouragement was noticed and that's when the teacher should give clues without giving the answer so that the students become engaged in the challenge again. Finally, in the social dimension, it was observed that showing the progress of each team in the board made students more encouraged and also made them want to hasten forward. This was an important factor for the mood and engagement shown by the students during the session [27].

\section{DISCUSSION}

The results show that in the end the students were able to establish the correspondence between mathematical model and the problematic situation in a more homogeneous way. The test results indicate that the performance at all stages is higher in the final evaluation except for the Mathematization phase but the variability is lower than the final evaluation. This is consonance with [8] who demonstrated that mathematical modelling is very complex for the students thanks to the cognitive demands associated to mathematical competences as strategies to solve problems, reading, communication and mathematical work. For this reason, the obtained result suggest that in spite of those difficulties that the students of this study show a ostensible progress in mathematical modeling .

The validation phase draws the attention because in spite of finding is higher mean score average in the final evaluation, the variability was also high. This means that students performed differently (in a less homogeneus way) than in the partial exam. A possible explanation leads us to think that students might feel more confident in the final evaluation since they trusted the results obtained in their calculators and therefore, they probably skipped the validation of results phase. [6] caution us this fact because the use of technological support such as calculators can sometimes "atrophy" arithmetical and geometric skills (p.58). Because of this, it is worth thinking of ways to show the students the importance of validation in their learning process and ensure that is put into practice.

Secondly, the failure to reject the null hypothesis allows us to corroborate that learning was sustained in the long run. In the teaching of mathematics this is an important issue to be considered because in final mathematics evaluations there is a tendency for students to forget core concepts that have been previously addressed in class. It is worth noticing that in the long-term learning was held at least at the phases 1, 2, 3, 4 and 7 of the model [8]. This definitely favors the implementation of challenge-based gamification as it positively influences significant learning enabling the connections between what the students already know and the new given information to implement the solutions to the modeling task.

Finally, the cognitive, emotional, and social elements were present in the gamified activity; the relevance of these dimensions were noticed thanks to the design context of the challenge-based gamification tasks. The challenges presented contributed to promote the cognitive dimension as well emotional dimension because the feedback was immediate. On the other hand, the use of leaderboard assisted student to interact among each other which facilitated sharing team achievements (social dimension). However, discouragement was also notices in some teams that gave up even when the teacher tried to provide instructional support to solve the task. This result was also found in [13, 18, 27, 28]. For the researchers gamification creates an environment where cognitive, emotional and social dimensions intersect. Again, Challenge-based gamificationn can be a seen as an optimal teaching strategy to favor mathematical learning.

\section{CONCLUSIONS}

This study had the objective of measuring the impact of challenge based gamification when it is applied to the computation of the volume of solids of revolution that rotates around $x$ axis employing the differential take strategy [1]. Based on the quantitative results, we conclude that there is no significant difference between partial and final tests in the mathematical modeling routes phases [7]: simplification, mathematization, mathematical work and presentation. Therefore, it is possible to claim that learning was kept long-term. Regarding the phases interpretation and validation, it is not possible to state that learning was kept but neither it can be said that the learning was higher or lower at the partial or final exams. However, this last result invites the teacher of this study to reflect about the way in which she can make sure her students interpret and validate their results. Even more important is to reinforce in the student the importance of the learning process for present and future. As claimed by [8] modeling studies, this process does not follows a lineal pattern, since we observed that the students went back and forth from one phase to another.

On the other hand, it is important to highlight gamification as a didactic strategy that attracts students to learning, however it has to be supported by a good didactic design and a reflexive process to allow continuous improvement [22, 26, 30, 34]. In this case, the offering of challenging activities was appealing and motivating to the students. Besides, they could put into practice their creative and collaborative skills $[2,3,23,25,32]$. This is why challenge based gamification was proposed. It is worth noting, that challenging activities must be carefully designed, because disappointment can come up if the students are asked to do more than they can based on their prior knowledge and skills. Challenge based gamification can be a double-edged sword if not enough time is spent in reflecting about the design [24].

Overall, this study demonstrates that cognitive, affective and social elements are essential aspects for the creation of gamified environments $[13,27,28]$. Further research would be required to better understand the processes relying underneath those dimensions. It would be also interesting to apply and study the challenge based gamification in a wider range of topics within the same subject.

Finally, we hypothesize that using a a quasi-experimental research design (i.e., control - experimental groups) in future studies could yield to more explicative results that help us to understand to what extent this strategy works better (or not) than traditional instruction. 


\section{ACKNOWLEDGMENTS}

This research has been realized inside Knowledge Society PhD Program of the Universidad de Salamanca, España.

\section{REFERENCES}

[1] Alanís, J. A., and Salinas, P. (2010). Cálculo de una variable: Acercamientos newtoniano y leibniziano integrados didácticamente. El Cálculo y su Enseñanza, 2, 1-14. Retrieved from http://mattec.matedu.cinvestav.mx/el calculo/index.php?vol=2\&index web=8\&index mgzne

[2] Angelini, M.L. y García-Carbonell, A. (2015). Percepciones sobre la integración de Modelos Pedagógicos en la Formación del Profesorado: La Simulación y Juego y El Flipped Classroom. Education in the Knowledge Society, 16(2), 16-30.

[3] Apple. (2010). Challenge Based Learning: A Classroom Guide. Apple Inc, 1-40. Retrieved from http://www.apple.com/br/education/docs/CBL_Classroom_Guide_Jan_2011.pdf

[4] Aretio, L. G., and España, U. (2016). El juego y otros principios pedagógicos . Supervivencia en la educación a distancia y virtual Its continued existence in distance and virtual education. RIED. Revista Iberoamericana de Educación a Distancia, 19(2016), 9-23. Retrieved from http://scholar.google.es/scholar_url?url=http://revistas.uned.es/index.php/ried/article/download/16175/14150\&hl=es\&sa=X\&scisig=A AGBfm0n-RIh4hFNdftp8_nEcMnSH80Auw\&nossl=1\&oi=scholaralrt

[5] Berland, L. K., Martin, T., Ko, P., Peacock, S. B., Rudolph, J. J., and Golubski, C. (2013). Student Learning in Challenge-Based Engineering Curricula. Journal of Pre-College Engineering Education Research, 3(1), 53-64.

[6] Blum, W. and Niss, M. (1991). Applied mathematical problem solving, modeling, applications, and links to other subjects - State, trends and issues in mathematics instruction. Educational Studies in Mathematics 22 (1), 37-68.

[7] Blum, W. and Leiß, D. (2007). How do students' and teachers deal with modelling problems? In: Haines, C. et al. (Eds), Mathematical Modelling: Education, Engineering and Economics. Chichester: Horwood , 222-231

[8] Borromeo, R. and Blum, W. (2009). Mathematical Modelling: Can it be taught and learnt? Journal of Mathematical Modelling and Application, 1 (1), 45-58.

[9] Brousseau, G. (1990). Utilidad e interés de la didáctica para un profesor (2da. Parte), SUMA (5), 5-12.

[10] Chamoso, J., Durán, J., García, J., Martín, J. and Rodríguez, M. (2004). Análisis y experimentación de juegos como instrumentos para enseñar matemáticas, SUMA, (47) 47-58.

[11] Creswel, J.W. (2015). A concise introduction to mixed methods research. Thousand Oaks, CA, USA: SAGE.

[12] Creswell, J. W, Plano Clark, V. L., Guttmann, M. L. and Hanson, E. E. (2003). Advanced mixed methods research design. En A.Tashakkori and C. Teddlie (Eds.). Handbook of mixed methods in social and behavioral research (pp. 209-240). Thousand Oaks, CA: Sage.

[13] Domínguez, A., Saenz-De-Navarrete, J., De-Marcos, L., Fernández-Sanz, L., Pagés, C., and Martínez-Herráiz, J. J. (2013). Gamifying learning experiences: Practical implications and outcomes. Computers and Education, 63, 380-392. http://doi.org/10.1016/j.compedu.2012.12.020

[14] Fidalgo, Á., and Sein-Echaluce, M. L. (2014). Educational innovation. Proceedings of the Second International Conference on Technological Ecosystems for Enhancing Multiculturality - TEEM '14, 17 (March), 65-67. Retrieved from http://dl.acm.org/citation.cfm?doid=2669711.2669880

[15] García-Peñalvo, F. J., García de Figuerola, C., and Merlo, J. A. (2010). Open knowledge: challenges and facts. Online Information Review, 34(4), 520-539.

[16] Gros Salvat, B., and Lara Navarra, P. (2009). Estrategias de innovación en la educación superior: el caso de la universitat oberta de catalunya. Revista Iberoamericana de Educación, (49), 223-245. Retrieved from file:///C:/Users/ROSALBA/Downloads/rie49a09.pdf

[17] Hamari, J., Shernoff, D. J., Rowe, E., Coller, B., Asbell-Clarke, J., and Edwards, T. (2016). Challenging games help students learn: An empirical study on engagement, flow and immersion in game-based learning. Computers in Human Behavior, 54, 170-179. Retrieved from http://linkinghub.elsevier.com/retrieve/pii/S074756321530056X

[18] Hanus, M. and Fox, J. (2014). Assessing the effects of gamification in the classroom: A longitudinal study on instrinsic motivation, social comparison, satisfaction, effort, and academis performance, Computers \& Education, (80) 152-161.

[19] Kaiser and Sriraman. (2006). A global survey of international perspectives on modeling in mathematics education. ZDM Mathematics Education. 38(3), 302-310

[20] Kebritchi, M., Hirumi, A., and Bai, H. (2010). The effects of modern mathematics computer games on mathematics achievement and class motivation. Computers \& Education, 55(2), 427-443. http://doi.org/10.1016/j.compedu.2010.02.007

[21] Maican, C., Lixandroiu, R., and Constantin, C. (2016). Interactivia.ro - A study of a gamification framework using zero-cost tools. Computers in Human Behavior, 61, 186-197.

[22] Marín, V. (2015). La gamificación educativa. Una alternativa para la enseñanza creativa. Digital Education Review, 27, 5-8. Retrieved from http://revistes.ub.edu/index.php/der/article/view/12486/pdf_1 
[23] Martin, T., Rivale, S. D., and Diller, K. R. (2007). Comparison of student learning in challenge-based and traditional instruction in biomedical engineering. Annals of Biomedical Engineering, 35(8), 1312-1323. http://doi.org/10.1007/s10439-007-9297-7

[24] Mas-Sansó, R., \& Manresa-Yee, C. (2016). Gamifying an artificial intelligence course in engineering education. International Journal of Engineering Education, 32(1), 513-520. Retrieved from http://www.scopus.com/inward/record.url?eid=2-s2.084959360874\&partnerID $=$ ZZOtx3y1

[25] Minović, M., García-Peñalvo, F. J., \& Kearney, N. A. (2016). Gamification in Engineering Education. International Journal of Engineering Education (IJEE), 32(1B), 308-309.

[26] Muñiz-Rodriguez, L., Alonso, P. and Rodriguez-Muñiz, L. (2014). El uso de los juegos como recurso didáctico para la enseñanza y el aprendizaje de las Matemáticas. Revista Iberoamericana de Educación Matemática, 39, 19-33. Retrieved from http://www.fisem.org/www/union/revistas/2014/39/archivo6.pdf

[27] Nisbet, S., and Williams, A. (2009). Improving students' attitudes to chance with games and activities. Australian Mathematics Teacher, 65(3), 25-37.

[28] Pulos, S., and Sneider, C. (1994). Designing and evaluating effective games for teaching science and mathematics: An illustration form coordinate geometry. Focus on Learning Problems in Mathematics 16(3), 23-42.

[29] Ramírez Montoya, M.S. (2015). Acceso abierto y su repercusión en la Sociedad del Conocimiento: Reflexiones de casos prácticos en Latinoamérica. Education In The Knowledge Society (EKS), 16(1), 103-118. doi:10.14201/eks2015161103118

[30] Rodríguez, F. and Santiago, R. (2015). Gamificación: cómo motivar a tu alumnado y mejorar el clima en el aula. Barcelona, España : Grupo Oceano.

[31] Sánchez, A.B., Mena, J., He, G. \& Pinto, J. (2013). Teacher development and ICT: The effectiveness of a training program for inservice school teachers. Procedia: Social and Behavioral sciences, 92, 529 - 534.

[32] Sánchez i Peris, F. J. (2015). Gamificación. Education in the Knowledge Society, 16(2), 13-15.

[33] Stefani, G., Andrés, L., and Oanes, E. (2014). Transformaciones lúdicas. Un estudio preliminar sobre tipos de juego y espacios lúdicos. Interdisciplinaria, 31(1), 39-55.

[34] Villalustre, L. and Del Moral, M-E. (2015) Gamificación: Estrategia para optimizar el proceso de aprendizaje y la adquisición de competencias en contextos universitarios. Digital Education Review, 27, 21- 39.Retrieved from http://revistes.ub.edu/index.php/der/article/view/12486/pdf_1 